\author{
Antoine G. Schneider \\ Rinaldo Bellomo
}

\section{Acute kidney injury: new studies}

Received: 24 January 2013

Accepted: 28 January 2013

Published online: 16 February 2013

(C) Springer-Verlag Berlin Heidelberg and ESICM 2013

A. G. Schneider · R. Bellomo (๘)

Intensive Care Unit, Austin Health, 145 Studley Road, Heidelberg, Melbourne, VIC 3084, Australia

e-mail: rinaldo.bellomo@austin.org.au

Tel.: +61-3-94965992

Fax: +61-3-94963932

A. G. Schneider

e-mail: antoine.schneider@austin.org.au

A. G. Schneider · R. Bellomo

Australian and New Zealand Research Centre,

Monash University, Melbourne, VIC, Australia

Acute kidney injury (AKI) is common in critically ill patients and independently associated with important morbidity and mortality [1]. However, its pathophysiology and optimal management remain largely unknown. In this brief review, we present recent advances in the understanding, prevention and management of AKI.

\section{Biomarkers}

In the last decade, several molecules have been identified as potential early biomarkers of renal injury [2-4]. A growing body of evidence suggests that, at least in some subgroups of patients, these biomarkers may allow earlier and, perhaps, more sensitive identification of AKI than current creatinine-based diagnostic criteria. In particular, a recent multicentre prospective cohort study [5] aimed to determine the diagnostic performance of several urinary biomarkers [neutrophil gelatinase-associated lipocalin (NGAL), kidney injury molecule 1 (KIM-1), interleukin (IL)-18, liver-type fatty acid binding protein and cystatin $\mathrm{C}$ ] to predict AKI when obtained in the emergency department (1,635 unselected patients). After exclusion of patients with minimal creatinine rise and rapid $(<72 \mathrm{~h})$ renal recovery, all biomarkers were elevated in patients with AKI. Urinary NGAL was found to be the most specific $(81 \%)$ and sensitive $(68 \%)$ biomarker (cut-off $104 \mathrm{ng} / \mathrm{ml}$ ) and to have good discriminatory ability for AKI. All tested biomarkers were found to have excellent negative predictive value $(>95 \%)$. Models including KIM-1 or urinary NGAL improved patient reclassification by more than $20 \%$ as compared with creatinine-based models.

Similar analyses performed in 380 cardiac surgery patients with post-operative AKI showed that three biomarkers (urinary IL-18, urinary albumin-to-creatinine ratio and urinary and plasma NGAL) were useful in predicting AKI progression [6]. Each biomarker was able to improve risk stratification and to identify patients at risk for progression of AKI, with plasma NGAL performing the best. Altogether, these data confirm previous findings in similar populations $[7,8]$.

Further studies are still required to determine the clinical utility of renal biomarkers in heterogeneous critically ill patients. However, renal-specific biomarkers have already improved our understanding of the pathophysiology of AKI. This is illustrated by another study, which challenged the concept of "pre-renal" AKI [9]. In 529 patients with measurements obtained at 0,12 and $24 \mathrm{~h}$ following intensive care unit admission, levels of urinary biomarkers (cystatin C, NGAL, $\gamma$-glutamyl transpeptidase, IL-18 and KIM-1) increased with AKI duration. In particular, pre-renal AKI - as defined by a rapid $(<48 \mathrm{~h})$ correction of uraemia and fractional sodium excretion $<1 \%$-was also associated with such elevations, only to 
a lesser extent. These findings suggest that pre-renal AKI is simply part of a continuum of injury and its reversibility can be more rationally and simply explained by the presence of less severe injury.

\section{Prevention of AKI}

In parallel, new strategies have been assessed for their ability to prevent cardiac surgery-associated AKI and contrast-induced AKI (CIAKI). A retrospective study [10] based on data from more than 700,000 patients found that off-pump coronary artery bypass graft (CABG) surgery was independently associated with decreased need for renal replacement therapy compared with standard onpump CABG. This strategy seemed to particularly benefit patients with poor preoperative renal function. This better renal outcome was, partly, further supported by the findings of a large (4,752 patients) randomised controlled trial (RCT) [11] where off-pump CABG was shown to decrease the risk of AKI [relative risk (RR) 0.87; $95 \%$ confidence interval (CI) 0.80-0.96]. However, this study with much higher evidence level did not show any decrease in the need for renal replacement therapy (RRT) or a survival advantage.

In 170 patients with chronic kidney disease who underwent coronary angiograms, a "furosemide with matched hydration" regimen was associated with a reduction in the risk of CIAKI compared with intravenous isotonic saline hydration [12]. Likewise, 100 patients with impaired renal function undergoing elective coronary angiography were randomly allocated to standard care or remote ischaemic preconditioning (obtained through four cycles of $5 \mathrm{~min}$ inflation and 5 min deflation of a blood pressure cuff) [13]. This intervention was associated with a lower incidence of CIAKI (40 versus $12 \%, p=0.002$ ) and was well tolerated. These interesting preliminary observations now need to be confirmed or refuted by larger multicentre studies.

\section{Fluids}

Two large RCTs have now compared $6 \%$ hydroxyl-ethyl starch (HES) with Ringer's lactate [14] or $0.9 \%$ saline [15] for fluid resuscitation in intensive care unit (ICU).
The first - the 6S study [14]—randomised 804 critically ill patients with severe sepsis and found that HES was associated with higher in-hospital mortality (RR 1.17; $p=0.03$ ) and increased use of renal replacement therapy (RR $1.35 ; p=0.04)$. The second-the CHEST trial [15] — randomised 7,000 critically ill patients and did not find a difference in mortality. However, it confirmed the increased need for renal replacement therapy in patients allocated to HES (RR $1.21 ; p=0.04$ ). In addition, HES was associated with increased serum creatinine levels and decreased urinary output in the first seven days after randomisation as well as a higher rate of adverse events (5.3 versus $2.8 \%, p=0.001$ ). Taken together and in the context of previous observations, these results confirm that HES fluid resuscitation should now be avoided in critically ill patients.

\section{Ultrafiltration}

Finally, in direct contrast with previous promising preliminary findings, in 188 patients with acute decompensated heart failure, worsened renal function (cardiorenal syndrome type 1) and persistent congestion, ultrafiltration was found to be inferior to a strategy of stepped pharmacologic therapy [16]. Indeed, it was associated with an increase in creatinine concentration $(+20.3$ versus $-3.5 \mu \mathrm{mol} / \mathrm{l}, p=0.003$ ), no difference in weight loss $96 \mathrm{~h}$ after enrolment, and a higher percentage of patients experiencing serious adverse events (72 versus $57 \%, p=0.03$ ). These findings strongly challenge the previously widely accepted utility of ultrafiltration in patients with congestive heart failure.

In conclusion, a potential diagnostic role for biomarkers of AKI is now slowly emerging. Off-pump CABG appears to be a possible approach for prevention of post-cardiac surgery AKI, but its use must be seen within the wider context of its other effects on the quality of coronary revascularization. New therapies are being tested which might attenuate CIAKI, and preliminary results are encouraging. Finally, large trials have confirmed the long-suspected nephrotoxicity of HES and dampened enthusiasm for the use of ultrafiltration in congestive heart failure.

Conflicts of interest The authors declare no conflicts of interest in relation to this study. 


\section{References}

1. Uchino S, Kellum JA, Bellomo R, Doig GS, Morimatsu H, Morgera S, Schetz M, Tan I, Bouman C, Macedo E, Gibney N, Tolwani A, Ronco C (2005) Acute renal failure in critically ill patients: a multinational, multicenter study. JAMA 294:813-818

2. Bellomo R, Kellum JA, Ronco C (2012) Acute kidney injury. Lancet 25(380):756-766

3. Bagshaw SM, Bennett M, Haase M, Haase-Fielitz A, Egi M, Morimatsu H, D'amico G, Goldsmith D, Devarajan P, Bellomo R (2010) Plasma and urine neutrophil gelatinase-associated lipocalin in septic versus non-septic acute kidney injury in critical illness. Intensive Care Med 36:452-461

4. Bagshaw SM, Langenberg C, Haase M, Wan L, May CN, Bellomo R (2007) Urinary biomarkers in septic acute kidney injury. Intensive Care Med 33:1285-1296

5. Nickolas TL, Schmidt-Ott KM, Canetta P, Forster C, Singer E, Sise M, Elger A, Maarouf O, Sola-Del Valle DA, O'Rourke M, Sherman E, Lee P, Geara A, Imus P, Guddati A, Polland A, Rahman W, Elitok S, Malik N, Giglio J, El-Sayegh S, Devarajan P, Hebbar S, Saggi SJ, Hahn B, Kettritz R, Luft FC, Barasch J (2012) Diagnostic and prognostic stratification in the emergency department using urinary biomarkers of nephron damage: a multicenter prospective cohort study. $\mathbf{J}$ Am Coll Cardiol 59:246-255

6. Koyner JL, Garg AX, Coca SG, Sint K, Thiessen-Philbrook H, Patel UD, Shlipak MG, Parikh CR, Consortium TA (2012) Biomarkers predict progression of acute kidney injury after cardiac surgery. J Am Soc Nephrol 23:905-914

7. Nickolas TL, O'Rourke MJ, Yang J, Sise ME, Canetta PA, Barasch N, Buchen C, Khan F, Mori K, Giglio J, Devarajan P, Barasch J (2008) Sensitivity and specificity of a single emergency department measurement of urinary neutrophil gelatinase-associated lipocalin for diagnosing acute kidney injury. Ann Intern Med 148:810-819
8. Haase-Fielitz A, Bellomo R, Devarajan P, Story D, Matalanis G, Dragun D, Haase M (2009) Novel and conventional serum biomarkers predicting acute kidney injury in adult cardiac surgery-a prospective cohort study. Crit Care Med 37:553-560

9. Nejat M, Pickering JW, Devarajan P, Bonventre JV, Edelstein CL, Walker RJ, Endre ZH (2012) Some biomarkers of acute kidney injury are increased in pre-renal acute injury. Kidney Int 81:1254-1262

10. Chawla LS, Zhao Y, Lough FC, Schroeder E, Seneff MG, Brennan JM (2012) Off-pump versus on-pump coronary artery bypass grafting outcomes stratified by preoperative renal function. J Am Soc Nephrol 23:1389-1397

11. Lamy A, Devereaux PJ, Prabhakaran D, Taggart DP, Hu S, Paolasso E, Straka Z, Piegas LS, Akar AR, Jain AR, Noiseux N, Padmanabhan C, Bahamondes JC, Novick RJ, Vaijyanath P, Reddy S, Tao L, Olavegogeascoechea PA, Airan B, Sulling TA, Whitlock RP, Ou Y, Ng J, Chrolavicius S, Yusuf S, Investigators C (2012) Off-pump or on-pump coronary-artery bypass grafting at 30 days. N Engl J Med 366:1489-1497

12. Marenzi G, Ferrari C, Marana I, Assanelli E, De Metrio M, Teruzzi G, Veglia F, Fabbiocchi F, Montorsi P, Bartorelli AL (2012) Prevention of contrast nephropathy by furosemide with matched hydration: the MYTHOS (Induced diuresis with matched hydration compared to standard hydration for contrast induced nephropathy prevention) trial. JACC Cardiovasc Interv 5:90-97

13. Er F, Nia AM, Dopp H, Hellmich M, Dahlem KM, Caglayan E, Kubacki T, Benzing T, Erdmann E, Burst V, Gassanov N (2012) Ischemic preconditioning for prevention of contrast medium-induced nephropathy: randomized pilot RenPro trial (Renal protection trial). Circulation 126:296303
14. Perner A, Haase N, Guttormsen AB, Tenhunen J, Klemenzson G, Aneman A, Madsen KR, Moller MH, Elkjaer JM, Poulsen LM, Bendtsen A, Winding R, Steensen M, Berezowicz P, SoeJensen P, Bestle M, Strand K, Wiis J, White JO, Thornberg KJ, Quist L, Nielsen J, Andersen LH, Holst LB, Thormar K, Kjaeldgaard AL, Fabritius ML, Mondrup F, Pott FC, Moller TP, Winkel P, Wetterslev J (2012) Hydroxyethyl starch 130/0.42 versus Ringer's acetate in severe sepsis. N Engl J Med 367:124-134

15. Myburgh JA, Finfer S, Bellomo R, Billot L, Cass A, Gattas D, Glass P, Lipman J, Liu B, McArthur C, McGuinness S, Rajbhandari D, Taylor CB, Webb SA (2012) Hydroxyethyl starch or saline for fluid resuscitation in intensive care. N Engl J Med 367:1901-1911

16. Bart BA, Goldsmith SR, Lee KL Givertz MM, O'Connor CM, Bull DA, Redfield MM, Deswal A, Rouleau JL, LeWinter MM, Ofili EO, Stevenson LW, Semigran MJ, Felker GM, Chen $\mathrm{HH}$, Hernandez AF, Anstrom KJ, McNulty SE, Velazquez EJ, Ibarra JC, Mascette AM, Braunwald E, Heart Failure Clinical Research N (2012) Ultrafiltration in decompensated heart failure with cardiorenal syndrome. N Engl J Med 367:2296-2304 